\title{
Tobacco point-of-sale advertising in Guatemala City, Guatemala and Buenos Aires, Argentina
}

\author{
Joaquin Barnoya, ${ }^{1,2}$ Raul Mejia, ${ }^{3}$ Debora Szeinman, ${ }^{3}$ Carlos E Kummerfeldt ${ }^{4}$
}

${ }^{1}$ Cardiovascular Unit of Guatemala, Guatemala ${ }^{2}$ Washington University in St Louis, School of Medicine, Missouri, USA

${ }^{3}$ Hospital de Clinicas, University of Buenos Aires. Buenos Aires, Argentina

${ }^{4}$ Aldo Castañeda Foundation. Guatemala

\section{Correspondence to}

Dr Joaquin Barnoya,

Cardiovascular Unit of

Guatemala, 6a Ave 8-71 zona

10, Clinica \#3, Ala Sur 01010,

Guatemala, USA;

jbarnoya@post.harvard.edu

Received 4 June 2009 Accepted 22 March 2010 Published Online First

7 June 2010

\begin{abstract}
Objectives To determine tobacco point of sale advertising prevalence in Guatemala City, Guatemala and Buenos Aires, Argentina.

Methods Convenience stores (120 per city) were chosen from randomly selected blocks in low, middle and high socioeconomic neighbourhoods. To assess tobacco point of sale advertising we used a checklist developed in Canada that was translated into Spanish and validated in both countries studied. Analysis was conducted by neighbourhood and store type.

Results All stores sold cigarettes and most had tobacco products in close proximity to confectionery. In Guatemala, $60 \%$ of stores had cigarette ads. High and middle socioeconomic status neighbourhood stores had more indoor cigarette ads, but these differences were determined by store type: gas stations and supermarkets were more prevalent in high socioeconomic status neighbourhoods and had more indoor cigarette ads. In poorer areas, however, more ads could be seen from outside the stores, more stores were located within 100 metres of schools and fewer stores had 'No smoking' or 'No sales to minors' signs. In Argentina, 80\% of stores had cigarette ads and few differences were observed by neighbourhood socioeconomic status. Compared to Guatemala, 'No sales to minors' signs were more prevalent in Argentina.
\end{abstract}

Conclusions Tobacco point of sale advertising is highly prevalent in these two cities of Guatemala and Argentina. An advertising ban should also include this type of advertising.

\section{INTRODUCTION}

Tobacco industry marketing campaigns have been instrumental in spreading the tobacco epidemic worldwide. Since the early 1970s, forseeing government tobacco advertising bans the industry noted that their brands would be 'dominantly displayed and advertised' at the point of sale. ${ }^{1} 2$ This type of advertising has been found to increase brand recognition, decrease smoking cessation attempts and to increase smoking relapse in former smokers. ${ }^{3-8}$ In adolescents, advertising at the point of sale increase smoking susceptibility, experimentation, and uptake. ${ }^{9}$ It has also been found to increase students' perception about the ease of purchasing cigarettes and decrease the likelihood of requiring proof of age. ${ }^{10}$ The USA, Australia, Canada, New Zealand and Malaysia have documented a high prevalence of tobacco point of sale advertising. ${ }^{3}{ }^{11-15}$ In the Americas region, aside from the Bahamas, Brazil, Canada, Jamaica, Mexico, Peru, Venezuela and the USA, most countries lack any government enforced advertising ban. Of these countries, only the Bahamas has banned point of sale advertising. ${ }^{16}$ In addition, tobacco point of sale advertising has not yet been documented in this region.

As of February 2009, Guatemala and Argentina lack comprehensive tobacco advertising bans. In Guatemala, advertising (written, graphic, radio, television, films and other electric or electronic media) requires prior authorisation of the Ministry of Public Health and Social Aid. In addition, tobacco billboards are banned within 500 metres of entrances and exits of pre-school, elementary or high schools. ${ }^{17}$ However, the tobacco industry (Philip Morris (PM) and British American Tobacco (BAT)) has voluntarily removed radio and television advertising. In Argentina, there is no national advertising ban and advertising is still allowed in newspapers, magazines, television and billboards. ${ }^{16}$ Since October 2005, the City of Buenos Aires has a tobacco advertising ban that includes newspapers, television, radio and billboards. ${ }^{18}$ This ban does not apply to the rest of the country. Regarding the point of sale, neither Guatemala nor Argentina has an advertising ban and retailers do not need a government licence to sell tobacco.

The objective of this study is to document the prevalence of tobacco point-of-sale advertising in the capital city of Guatemala (Guatemala City) and Argentina (Buenos Aires).

\section{METHODS}

From March to May 2008, we selected 240 (120 per country) convenience stores in Guatemala City, Guatemala, and Buenos Aires, Argentina, without any prior knowledge of whether they sell cigarettes or about the presence of tobacco point-of-sale advertising. Because others have found tobacco point-of-sale advertising is more prevalent in less privileged neighbourhoods, we selected our sample based on socioeconomic neighbourhood. ${ }^{1920}$ To get stores from high, middle and low socioeconomic status (SES) neighbourhoods, we selected one neighbourhood from each of these three rankings. In Guatemala, to define neighbourhood SES, we used the average unit price of land defined by the Municipalidad de Guatemala. We then located the three different SES neighbourhoods in Mapquest. In Argentina, we used the 2007 Encuesta Nacional de Hogares de Buenos Aires (National Home Survey of Buenos Aires). We then used a random digit generator to identify 30 blocks per SES neighbourhood in each city where stores would be evaluated. Every store in each block was evaluated, and when a block had no store, the next adjacent block was chosen. All stores in each block were evaluated.

To assess the prevalence and characteristics of point of sale advertising in stores we used unlocked scheme, see http:// tobaccocontrol.bmj.com/site/ about/unlocked.xhtml 
a checklist developed by Cohen and Di Nardo in Canada. ${ }^{11}$ The checklist, designed to be completed in no more than 10 minutes, assesses the tobacco advertising type, feature, brand, location and displays within each store. In addition, the observer estimated the percentage of space in front of the client occupied by tobacco advertising and if tobacco products or advertising were located less than 50 centimetres of confectionary. After obtaining permission from the authors, we translated and adapted the checklist to Spanish. Then it was pilot tested in Argentina and Guatemala and found to be appropriate.

We used SPSS (version 11.0, 2001) to enter and analyse data. Analyses were done primarily with $\chi^{2}$ testing (nominal variables) and analysis of variance (ANOVA, interval variables). Percentage of space in front of the client occupied by tobacco advertising is reported as mean (SD) for each store type and neighbourhood SES. In Guatemala, data were first analysed by SES and then by store type. In Argentina, given that there were only two types of stores surveyed (small $(15 \%)$ and big ( $85 \%)$ stores) and the location of these stores did not differ by neighbourhood, data were only analysed by neighbourhood SES.

\section{RESULTS}

A total of 120 stores were surveyed in each city. All stores in Guatemala and Argentina sold cigarettes. Sixty per cent of stores in Guatemala and $78 \%$ in Argentina had cigarette advertising $(\mathrm{p}=0.003)$. In Guatemala, in the high SES neighbourhoods, most stores evaluated were gas stations; while in the middle and low SES neighbourhoods they were small stores (table 1).

In Guatemala, very few stores had exterior ads and the proportion did not vary by neighbourhood $(p=0.08)$. By contrast, most had interior ads and tobacco products in close proximity to confectionary (table 2). The number of interior ads differed significantly by area with a tendency for more ads in the higher SES neighbourhood (table 2). Yet 'No smoking' or 'No sales to minors' signs were also more frequent in this neighbourhood. By contrast the low SES neighbourhood had a significantly greater proportion of ads that could be seen from outside the store and were more likely to have stores within 100 metres of a school. Most stores had tobacco products close to confectionary, except stores in the middle SES where only $38 \%$ of stores did $(\mathrm{p}=0.002)$. It appears, however, that these neighbourhood differences were largely determined by store type, notably the predominance of gas stations in the high SES neighbourhood and small stores in low and middle SES neighbourhoods (table 3). Gas stations had significantly greater

Table 1 Store type by city and socioeconomic neighbourhood, 2008

\begin{tabular}{lcccc}
\hline & \multicolumn{4}{l}{ Percentage of stores in each neighbourhood* } \\
\cline { 2 - 5 } & No of stores & $\begin{array}{l}\text { High } \\
(\mathbf{n}=\mathbf{4 0})\end{array}$ & $\begin{array}{l}\text { Middle } \\
(\mathbf{n}=\mathbf{4 0})\end{array}$ & $\begin{array}{l}\text { Low } \\
(\mathbf{n}=\mathbf{4 0})\end{array}$ \\
\hline Guatemala $(\mathrm{n}=20)$ & & & & \\
$\quad$ Big store/pharmacy & 8 & 18 & & 3 \\
$\quad$ Small store $\dagger$ & 88 & 27 & 100 & 92 \\
$\quad$ Gas stations & 17 & 42 & & \\
$\quad$ Supermarket & 7 & 12 & & 5 \\
Argentina (n=120) & & & & \\
$\quad$ Big store & 100 & 80 & 87 & 82 \\
$\quad$ Small store & 20 & 20 & 3 & 8 \\
\hline
\end{tabular}

*Percentages do not add up to 100 owing to rounding.

†In Guatemala: A small store is wooden, made and located on sidewalks. Big stores are permanent constructions and have a larger variety of products. In Argentina: In small stores purchase is made through a window while the customer stands on the sidewalk. Only in big stores customers walk through the store to pick up groceries.

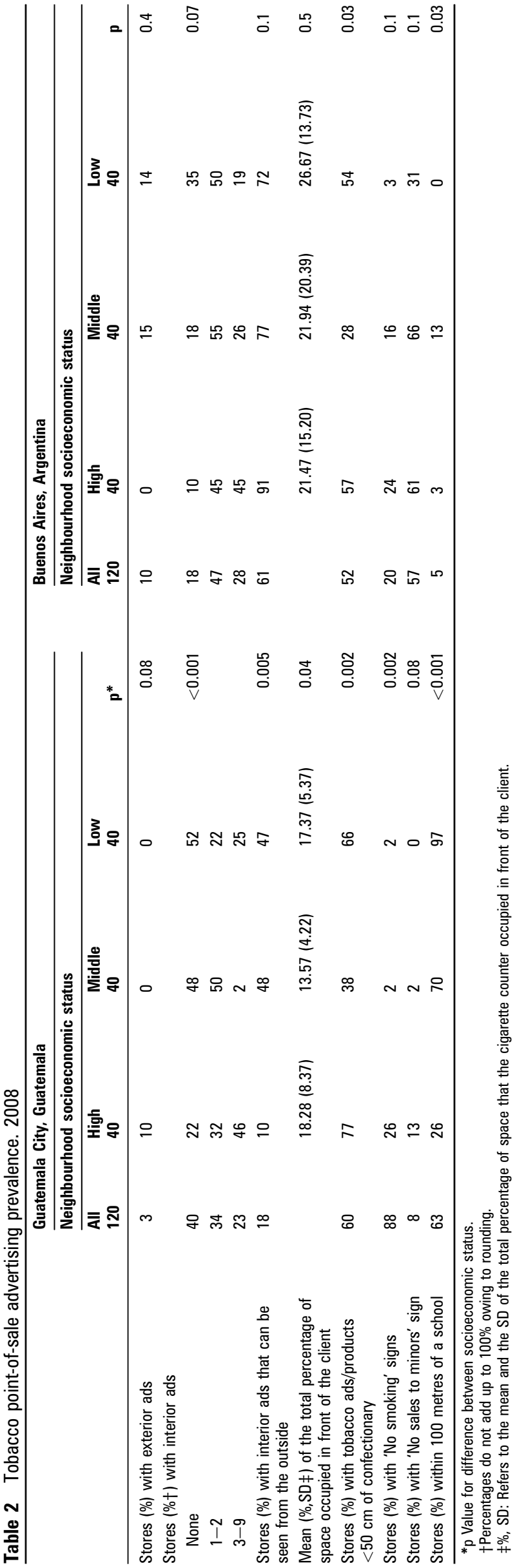


Table 3 Point-of-sale advertising by store type in Guatemala City. 2008

\begin{tabular}{|c|c|c|c|c|c|}
\hline & $\begin{array}{l}\text { Big store/pharmacy } \\
8\end{array}$ & $\begin{array}{l}\text { Small store } \\
88\end{array}$ & $\begin{array}{l}\text { Gas station } \\
17\end{array}$ & $\begin{array}{l}\text { Super market } \\
7\end{array}$ & $\mathbf{p}$ \\
\hline Stores with exterior ads (\%) & 0 & 0 & 24 & 0 & $<0.001$ \\
\hline Stores $\left(\%{ }^{*}\right)$ with interior ads. & & & & & $<0.001$ \\
\hline $1-2$ & 63 & 34 & 19 & 33 & \\
\hline $3-9$ & 12 & 12 & 81 & 68 & \\
\hline Stores (\%) with interior ads than can be seen from the outside. & 0 & 29 & 13 & 17 & 0.1 \\
\hline Stores (\%) with 'No smoking' signs & 14 & 2.3 & 56 & 0 & $<0.001$ \\
\hline Stores (\%) with 'No sales to minors' signs & 0 & 2.3 & 25 & 0 & 0.002 \\
\hline Stores (\%) within 100 metres of a school & 14 & 77 & 25 & 57 & $<0.001$ \\
\hline
\end{tabular}

*Percentages do not add up to $100 \%$ owing to rounding.

$\dagger \%$, SD: Refers to the mean and the SD of the total percentage of space that the cigarette counter occupied in front of the client.

numbers of large, indoor ads occupying more space while most small stores did not have 'No sales to minors' signs, but were more likely to be located within 100 metres of a school.

In Argentina, few stores had exterior ads and the percentage of stores with interior ads did not differ significantly by neighbourhood SES (table 2). However, a lower percentage of stores in high and middle SES did not have any interior ads compared to stores in the low SES. In all the different SES neighbourhoods, most stores have interior ads that can be seen from the outside. The percentage of space in front of the client occupied by tobacco ads did not differ across neighbourhood SES. More stores in the high and middle SES neighbourhoods did have 'No sales to minor' signs compared to stores in the low SES $(p=0.1)$. Half the stores in high and low SES neighbourhoods have tobacco products in close proximity to confectionary compared to $28 \%$ of those in the middle SES ( $p=0.03$ ). Regarding store location in relation to schools, most stores were not located within 100 metres of a school. Analysis by store type did not yield any significant differences (results not shown).

In Guatemala, cigarettes were displayed on top of the counter in $100 \%$ of big stores, $54 \%$ of small stores and $83 \%$ of supermarkets. Only in gas stations, most (56\%) cigarettes were displayed behind the counter, but still in sight. In Argentina, cigarettes were displayed on top of the counter in $90 \%$ of big stores and in $77 \%$ of small stores.

In Guatemala, most of the advertising was dominated by BAT (Pall Mall was the most common brand advertised) as opposed to Argentina, where it was dominated by PM (Marlboro was the most common brand advertised).

\section{DISCUSSION}

In these two Latin American cities in Guatemala and Argentina, tobacco point-of-sale advertising is highly prevalent. In Guatemala prevalence appears to be related to store type rather than neighbourhood SES. In the USA, convenience, convenience/gas and liquor stores have been found to have higher prevalence of tobacco point-of-sale advertising compared to grocery stores and pharmacies. ${ }^{21}$ Similarly, in Canada, chain convenience stores had the largest amount of tobacco point-ofsale advertising. ${ }^{11}$

Tobacco product placement in close proximity to confectionary was highly prevalent in both cities. It has been suggested that such placement encourages the young to see tobacco as benign and commonplace in the market like confectionary. ${ }^{2}$ In addition, cigarettes were placed in prime locations, behind the cashier and on the counter-top, positions for which retailers usually charge a premium. ${ }^{1}$

\section{What this paper adds}

Tobacco point-of-sale advertising has been found to increase brand recognition and adolescents' perception about the ease of purchasing cigarettes. In the USA, Canada, Australia and Malaysia, a high prevalence of tobacco point-of-sale advertising has been documented. Guatemala and Argentina are two Latin American countries that lack comprehensive advertising bans. Consistent with findings elsewhere, we document a high prevalence of tobacco point-of-sale advertising in Guatemala and Argentina. These countries need comprehensive advertising bans that include point-of-sale restrictions.

We also assessed the presence of the tobacco industry's 'No sales to minors' signage. In Guatemala, fewer stores had the signage compared to Argentina where most stores did. In the USA, PM requires the placement of this signage in stores that participate in the Retail Leaders Program. Given that PM brands dominated the Argentinian point-of-sale environment, this might help explain the difference with Guatemala. However, these youth access programmes do not affect teen smoking prevalence. ${ }^{22} 23$

Our study has strengths and limitations. To our knowledge, it is the first study to document the prevalence of tobacco point of sale advertising in two Latin American countries. We randomly selected stores from different SES neighbourhoods but used neighbourhood as a proxy for SES, when it may, in fact, vary by block. In Guatemala, where the WHO Framework Convention on Tobacco Control (FCTC) has been ratified, we do not have data pre-FCTC and post-FCTC ratification to assess whether the prevalence of point of sale advertising has changed since ratification. Regardless of these limitations, none of them should be a source of bias or limit the policy implications of our study.

In conclusion, tobacco point-of-sale advertising is highly prevalent in the capital cities of Guatemala and Argentina. Both countries as FCTC signatories should be committed to apply Article 13 and 'undertake a comprehensive ban of all tobacco advertising, promotion and sponsorship.'(emphasis added). ${ }^{24}$ Our data underline the importance of ensuring that point-of-sale advertising is included when a tobacco advertising ban is proposed in either country.

Acknowledgements We thank Jose Carlos Monzón who collaborated with data collection in Guatemala. Maria Alegre provided information regarding marketing strategies. In addition, Joanna Cohen granted us permission to use the point-of-sale checklist. 
Funding This work was carried out with the aid of a grant from the Research for International Tobacco Control (RITC) program of the International Development Research Centre (IDRC) in Ottawa, Canada. Joaquin Barnoya is partially supported by an unrestricted grant from the American Cancer Society.

Competing interests None.

Contributors RM and JB conceived the study and lead the data analysis. JB took the lead in manuscript writing. DS and CK pilot tested the survey and contributed to data analysis. All authors have approved the final version of the manuscript.

Provenance and peer review Not commissioned; externally peer reviewed.

\section{REFERENCES}

1. Lavack AM, Toth G. Tobacco point-of-purchase promotion: examining tobacco industry documents. Tob Control 2006:15:377-84.

2. Pollay RW. More than meets the eye: on the importance of retail cigarette merchandising. Tob Control 2007;16:270-4.

3. Donovan RJ, Jancey J, Jones S. Tobacco point of sale advertising increases positive brand user imagery. Tob Control 2002;11:191-4

4. Schooler C, Feighery E, Flora JA. Seventh graders' self-reported exposure to cigarette marketing and its relationship to their smoking behavior. Am J Public Health 1996;86:1216-21.

5. Redmond WH. Effects of sales promotion on smoking among U.S. ninth graders. Prev Med 1999:28:243-50.

6. Henriksen L, Feighery EC, Wang $Y$, et al. Association of retail tobacco marketing with adolescent smoking. Am J Public Health 2004;94:2081-3.

7. Wakefield MA, Ruel EE, Chaloupka FJ, et al. Association of point-of-purchase tobacco advertising and promotions with choice of usual brand among teenage smokers. J Health Commun 2002;7:113-21.

8. Slater SJ, Chaloupka FJ, Wakefield M, et al. The Impact of Retail Cigarette Marketing Practices on Youth Smoking Uptake. Arch Pediatr Adolesc Med 2007:161:440-5.

9. Paynter J, Edwards R. The impact of tobacco promotion at the point of sale: A systematic review. Nicotine \& Tobacco Research 2009;11:25-35.
10. Wakefield M, Germain D, Durkin S, et al. An experimental study of effects on schoolchildren of exposure to point-of-sale cigarette advertising and pack displays. Health Educ Res 2006;21:338-47.

11. Cohen JE, Planinac LC, Griffin K, et al. Tobacco promotions at point-of-sale: the last hurrah. Can J Public Health 2008;99:166-71.

12. Jalleh G, Donovan RJ. Tobacco advertising and promotion at point-of-sale. Australian and New Zealand Journal of Public Health 2006:30:579-80.

13. Paynter J, Freeman B, Hughes B. Bringing down the powerwall: a review of retail tobacco displays. Auckland, New Zealand, 2006.

14. Yoke KL, Kin F, Lian TY. Surveillance of tobacco industry marketing strategies at retail outlets. Penang, Malaysia: Research Network for Tobacco Control, 2008

15. Wakefield MA, Terry-McElrath YM, Chaloupka FJ, et al. Tobacco industry marketing at point of purchase after the 1998 MSA billboard advertising ban. Am J Public Health 2002;92:937-40.

16. World Health Organization. WHO Report on the global tobacco epidemic, 2008. Geneva: the MPOWER package, 2008.

17. Shafey 0, Dolwick S, Guindon GE, eds. Tobacco control country profiles. American Cance Society, Atlanta, GA, 2003.

18. Ministerio de Salud. Programa Nacional de Control de Tabaco. Buenos Aires: Presidencia de La Nacion, 2009. http://www.msal.gov.ar/htm/site tabaco/ legislacion.asp (accessed 12 May 2009).

19. Barbeau EM, Wolin KY, Naumova EN, et al. Tobacco advertising in communities: associations with race and class. Prev Med 2005:40:16-22.

20. Laws MB, Whitman J, Bowser DM, et al. Tobacco availability and point of sale marketing in demographically contrasting districts of Massachusetts. Tob Control 2002;11(Suppl 2):ii71-3.

21. Center for Disease Control and Prevention. Points-of-purchase tobacco environments and variation by store type - United States, 1999. MMWR 2002:51:184-7.

22. Jones SE, Sharp DJ, Husten CG, et al. Cigarette acquisition and proof of age among US high school students who smoke. Tob Control 2002;11:20-5.

23. Ling PM, Landman A, Glantz SA. It is time to abandon youth access tobacco programmes. Tob Control 2002;11:3-6.

24. Conference of the parties to the WHO FCTC. WHO framework convention on tobacco control. Geneva, Switzerland: World Health Oraganization, 2003. http:// www.who.int/fctc/text_download/en/index.html (accessed 30 Mar 2009). 